\title{
DETERMINATION OF THE WEIGHT AVERAGE MOLECULAR WEIGHT OF SRM 1480
}

Charles M. Guttman John R. Maurey Peter H. Verdier

U.S. DEPARTMENT OF COMMERCE Technology Administration National Institute of Standards and Technology Institute for Materials Science and Engineering Polymers Division Gaithersburg, MD 20899

$-Q C$ 



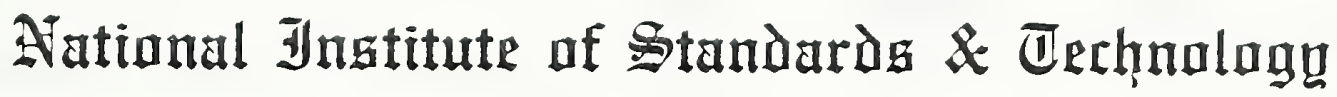

\section{(Tertificate of Analggita}

\section{Standard Reference Material 1480}

\section{Polyurethane}

This Standard Reference Material (SRM) is intended for the calibration and evaluation of instruments used in polymer technology and science for the determination of molecular weight and for use as a characterized sample for measurements of other physical properties of polyurethane. The SRM is supplied as a liquid weighing approximately $1 \mathrm{~g}$. The certified value for the weight-average molecular weight was determined by light scattering to be:

$$
M_{w}=47.3 \times 10^{3} \mathrm{~g} \cdot \mathrm{mol}^{-1}
$$

The standard deviation of this value, based on 4 degrees of freedom, is:

$$
S_{x}=3.3 \times 10^{3} \mathrm{~g} \cdot \mathrm{mol}^{-1} \text {. }
$$

The systematic error of this determination is not expected to exceed 15 percent.

The values for limiting viscosity number and for the ratio of $M_{w}$ to $M_{n}$ (number-average molecular weight) are not certified, but are for information only. The limiting viscosity number of SRM 1480 in tetrahydrofuran at $30^{\circ} \mathrm{C}$ was found to be $43.8 \mathrm{~mL} \cdot \mathrm{g}^{-1}$ with a standard deviation of $0.2 \mathrm{~mL} \cdot \mathrm{g}^{-1}$. A ratio of $\mathrm{M}_{w}$ to $\mathrm{M}_{\mathrm{n}}$ of 2.3 was estimated from apparent polystyrene molecular weights obtained from Size Exclusion Chromalography.

Notice and Warnings to Users:

Expiration of Certification: This certification will be valid for two years from the date of shipment.

Storage: SRM 1480 should be stored under dry nitrogen in the original bottle, tightly closed, in the dark, and under normal laboratory temperatures.

\section{Note to Users:}

This material is in the form of an extremely viscous liquid. Details of the preparation, handling and measurements for this SRM are described in "Determination of the Weight Average Molecular Weight of SRM $1480^{n}$ which is included with this SRM.

Measurements leading to the certification of this Standard Reference Material were performed by C.M. Guttman, J.R. Maurey and P.H. Verdier of the Polymers Division.

The overall direction and coordination of the technical measurements leading to certification were performed by C.C. Han, Leader, Polymer Blends and Solution Group, Polymers Division.

The technical and support aspects involved in the preparation, certification, and issuance of this Standard Reference Material were coordinated through the Standard Reference Materials Program by J.C. Colbert. 


\section{REFERENCE}

[1] C.M. Guttman, J.R. Maurey, and P.H. Verdier, "Determination of the Weight Average Molecular Weight of SRM 1480", NIST IR 4837, 1992. 


\section{DETERMINATION OF THE WEIGHT AVERAGE MOLECULAR WEIGHT OF SRM 1480}

Charles M. Guttman

John R. Maurey

Peter H. Verdier

U.S. DEPARTMENT OF COMMERCE Technology Administration National Institute of Standards and Technology

Institute for Materials Science and Engineering

Polymers Division

Gaithersburg, MD 20899

Report to FDA and SRMP

July 1992

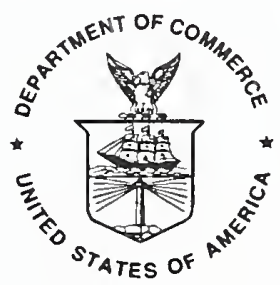

U.S. DEPARTMENT OF COMMERCE

Barbara Hackman Franklin, Secretary

TECHNOLOGY ADMINISTRATION

Robert M. White, Under Secretary for Technology

NATIONAL INSTITUTE OF STANDARDS

AND TECHNOLOGY

John W. Lyons, Director 



\section{ABSTRACT}

The characterization of a polyurethane standard reference material, SRM 1480, is described. The weight-average molecular weight of SRM 1480 by light scattering was determined to be $4.73 \times 10^{4} \mathrm{~g}^{\cdot} \mathrm{mole}^{-1}$ with a sample standard deviation of the mean of $0.33 \times 10^{4} \mathrm{~g} \cdot \mathrm{mole} \mathrm{e}^{-1}$, based on 4 degrees of freedom. A systematic error limit of $15 \%$ is estimated for this determination. The intrinsic viscosity of SRM 1480 in THF was also measured.

The Size Exclusion Chromatography (SEC) of SRM 1480 in THF as received in the bottle was found to exhibit concentration dependent peak

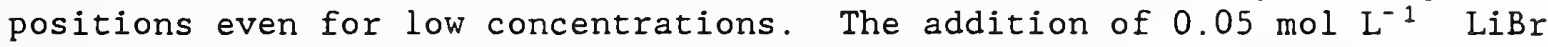
to the THF was found to alleviate this problem. This low concentration of LiBr did not change the Polystyrene calibration of the SEC columns. 



\subsection{Introduction}

There is a growing need for better methods of characterizing the commercial polyurethanes used in medical devices, both before use and after degradation following implantation. Because of the wide variations in the compositions of these block copolymer systems, the usual methods for determining molecular weight distribution (MWD) are of limited applicability and are difficult to interpret. With support from the Food and Drug Administration (FDA) and the Standard Reference Materials Program (SRMP), we undertook a program to develop improved methods for characterizing polyurethanes and other block copolymer systems through the production of polyurethane Standard Reference Materials (SRMs).

This report describes extensive work on the certification of the weight average molecular weight of a low molecular weight Polyurethane SRM, SRM 1480. The limiting viscosity number determined under conditions commonly used for the estimation of MWD by Size Exclusion Chromatography (SEC), has been determined as a supplemental number.

2.0 Preparation, Bottling, and Handling of SRM 1480

\subsection{Preparation}

The low molecular weight standard, SRM 1480, is not the usual commercial polyurethane, but rather is a model compound that could be treated as a homopolymer from the point of view of absolute molecular weight determination methods. The polymer was made by reacting a narrow MWD polyethylene glycol (PEG 600) with purified diphenylmethane-4,4'diisocyanate (MDI) (Dow Chemical Company designation xpr-270-0010-27-1).1

This polymer has a well defined repeat unit designated (MDI-PEG 600) n. It thus could be treated as a homopolymer in either sedimentation or light scattering methods. This material differed from a normal polyurethane in that it had no chain extender.

The material was made at Dow Chemical, Connecticut, under the direction of $\mathrm{Dr}$. Curtis Smith. The received material was in the form of a gum.

\subsection{Homogeneity Testing on SRM 1480}

The material, as received, was found to be inhomogeneous. The method of homogenization and bottling was described in an earlier report [1] . 324 samples were bottled. The entire set of samples was divided into 15 subsets. One vial was randomly selected from each subset for homogeneity testing. The weight of polymer in each of these 15 bottles was determined

${ }^{1}$ Certain commercial materials and equipment are identified in this paper in order to specify adequately the experimental procedure. In no case does such identification imply recommendation or endorsement by the National Institute of Standards \& Technology, nor does it imply necessarily the best available for the purpose. 
to be over 1 gram ( 1.1 to 1.3 grams). From each of these 15 bottles a solution of polymer in THF was made for a SEC run.

The chromatograms from these runs superimpose on each other. Figure 1 shows some of these chromatograms. There was no way to distinguish among the 15 samples on the basis of their chromatograms except for some small difference at very low molecular weight where we also experience interference from additives to the solvent THF, Butyl-hydroxytoluene (BHT), or from residual methylene chloride. Thus, we consider the material homogeneous.

\section{3 Handling of SRM 1480}

SRM 1480 is a stiff, highly viscous fluid which adheres easily to most materials. This made handling difficult. To prepare a solution, we used a stiff spatula with a small tip to extract sample from the bulk of the viscous gum. The sample stuck tenaciously to the tip of the spatula during transfer from the sample vial to the preweighed solution bottle. The gum sample was pressed to the lower wall of the solution bottle until it adhered; the spatula tip was then pulled free by twisting the spatula. The sample weight was determined by reweighing the bottle containing the sample. Solvent was then added. After completion of sampling, the sample vial was flushed with a stream of dry nitrogen and then capped tightly. Several samples were taken in this manner from each of the sample vials during the months of characterization experiments without any detectable change in the polymer.

\subsection{Limiting Viscosity Number of SRM 1480 in THF}

The viscosity number as a function of concentration was obtained from flow time measurements at $30^{\circ} \mathrm{C}$ at concentrations of about $0.0025,0.0050$, and $0.0075 \mathrm{~g} / \mathrm{mL}$ in tetrahydrofuran (THF). The viscometer used was a Cannon Ubbelohde semi-micro viscometer (Cannon \# K 546) with a maximum shear rate of about $1800 \mathrm{~s}^{-1}$. At least $0.1 \mathrm{~g}$ sample of polyurethane was used to prepare each solution. The solvent, Mallinckrodt Tetrahydrofuran (stabilized) AR (Analytical Reagent), was used as received. All solvents and solutions were filtered through BIORAD (catalog \#343-0001) 0.45 $\mathrm{m}$ prep-disc membrane filters.

Two independently prepared solutions were run at each concentration. The viscosity number plotted against concentration appears linear to a concentration of at least $0.004 \mathrm{~g} / \mathrm{mL}$. On the basis of these results we estimated the limiting viscosity number of SRM 1480 to be $43.8 \mathrm{~mL} / \mathrm{g}$ with a standard deviation of $0.17 \mathrm{~mL} / \mathrm{g}$. Table 1 and figure 2 give the data used in the fit [1].

Since we have not certified the intrinsic viscosity no effort was made to make a detailed systematic error analysis of this quantity. However from previous work using a similar viscometer, we estimate the systematic error limit to be about $2 \%$. 


\subsection{SEC on Low Molecular Weight Standard, SRM 1480.}

Since this polyurethane was designed to be used as a SEC standard it is important that its behavior be normal in the SEC environment. If its behavior is unusual, we need to find the conditions under which it becomes normal. Without controlling this behavior, SRM 1480 would not be a useful SEC calibrant.

In all of the following discussion on SEC studies, a Waters 150-C ALC/GPC Liquid Chromatograph with a refractive index (RI) detector was used. Unless otherwise specified Mallinckrodt THF was used as the solvent and two Polymer Labs PL-gel $10 \mu \mathrm{m}$ Mixed Bed columns were used.

\subsection{Concentration Studies}

Early studies on the concentration effect of the SEC of SRM 1480 showed that at fixed injection volume the leading edge of the SEC peak varied with concentration, changing from an elution volume of $15.98 \mathrm{~mL}$ for $0.002 \mathrm{~g} / \mathrm{mL}$, to $16.18 \mathrm{~mL}$ for $0.0005 \mathrm{~g} / \mathrm{mL}$, to $16.4 \mathrm{~mL}$ for $0.00025 \mathrm{~g} / \mathrm{mL}$. During all of these runs, the peak position remained at $16.6 \mathrm{~mL}$ and the following edges for all concentrations were constant. See figure 3 for an example of these data. At the same time Polystyrene (PS) of molecular weight $\left(M_{w}\right) 36,950$ was run at concentrations of $0.0005 \mathrm{~g} / \mathrm{mL}$ to 0.00002 $\mathrm{g} / \mathrm{mL}$. This polymer had an elution volume in the same range as SRM 1480 . The PS chromatograms showed random peak shifts of less than $0.07 \mathrm{~mL}$. This shift is about the error expected from the data collection rate used at that time, and smaller than the edge shifts observed on the SRM 1480 .

Additional studies of the effect of concentration on the peak position and peak shape of the SEC of SRM 1480 have been made. Different columns from the same and different manufacturers were tried. The effect of column loading and the addition of controlled amounts of water were studied to see their effect on this problem. None of these were effective in improving the shape or repeatability of the peak position as a function of concentration [1].

A number of studies of polyurethanes have suggested that the addition of salts to the solvents dimethyl formamide (DMF) or dimethyl acetamide (DMAC) improved the SEC [2]. None of the earlier studies described the concentration effects we found. Rather they found that salts like $\mathrm{LiBr}$ in DMF seemed to improve the shape of the SEC curves. Use of salts in THF as a SEC solvent has been reported, but these reports were not concerned with polyurethanes [3].

We repeated the SEC studies using THF containing $0.01 \mathrm{~mol} / \mathrm{L} \mathrm{LiBr}$. Concentrations of SRM 1480 from $0.002 \mathrm{~g} / \mathrm{mL}$ to $0.0005 \mathrm{~g} / \mathrm{mL}$ in THF with 0.01 mol/L LiBr were run. These solutions gave SEC curves which superimpose on each other and showed no shape or peak position dependence on concentration in THF with $0.01 \mathrm{~mol} / \mathrm{L} \mathrm{LiBr}$. Figure 4 shows an example of our data using this solvent. We therefore suggest that SRM 1480 be used as a standard reference material in the calibration of SEC columns only when it is used in THF with $0.01 \mathrm{M} \mathrm{LiBr}$ added. 


\subsection{Apparent Polystyrene Molecular Weight from SEC}

The SEC of SRM 1480 was run as described in section 4.1 with 0.01 $\mathrm{LiBr}$ in THF. The columns were calibrated with polystyrene fractions from an Easi-cal tab from Polymer Labs and with SRM 1478 and SRM 1479. We found that the calibration of the SEC by polystyrene in THF, with and without $0.01 \mathrm{M} \mathrm{LiBr}$, was the same within the error of the data collection.

From these calibrations we estimated the polystyrene equivalent molecular weights $\left(M_{i}\right)_{\text {ap }}$ of SRM 1480 as

$$
\begin{aligned}
& \left(M_{n}\right)_{\text {ap }}=2.6 \times 10^{4} \mathrm{~g} \mathrm{~mole}-1 \\
& \left(M_{w}\right)_{\text {a }}=6.0 \times 10^{4} \mathrm{~g} \mathrm{~mole}-1 \\
& \left(\mathrm{M}_{\mathrm{z}}\right)_{\mathrm{ap}}=1.0 \times 10^{5} \mathrm{~g} \mathrm{~mole} \mathrm{e}^{-1}
\end{aligned}
$$

5.0 Determination of Molecular Weight of SRM 1480 by Light Scattering

\subsection{Estimation of Degradation Rate by Light Scattering}

By their nature light scattering experiments are of short duration. A number of solutions can be prepared and run by light scattering in a single day. To check for degradation, several solutions were made up and run a number of times during one day. They were then stored in the dark and run two days later, four days later, and a week later. The apparent molecular weights of these solution were found to change by less than $5 \%$ after standing 12 hours and by less than $15 \%$ after standing a week.

As long as we prepare fresh solutions and run them within a day or two, we expect no problem. This was our practice during the entire series of light scattering experiments.

Additional studies on the degradation of SRM 1480 in DMAC were made by running the SEC after storing the solution for a known time. These studies, which are described in a previous report [1], showed a shift in the SEC peak only after the solutions were stored in the dark for more than a week.

\subsection{Light scattering on the Low Molecular Weight Polyurethane Standard}

\subsubsection{Solution and Solvent preparation}

Burdick and Jackson DMAC was used as the solvent. Since DMAC is hygroscopic, care was taken to open the solvent bottle in a dry box and to do as much of the sample preparation as possible in the dry box.

Polar solvents such as water are very difficult to make dust free for light scattering measurements. It was found that the DMAC has a great proclivity to hold dust, also. 
Before each use, the light scattering cells were cleaned in a xylene vapor chamber in which the condensing vapors removed the dust from the surface of the cells. Filtering with a single 0.22 micron filter was unsuccessful in cleaning the dust out of the solution when the filtration was done in the dry box. Dust was stirred up in the dry box by the cyclic transfer of dry $\mathrm{N}_{2}$ in and out of the entrance lock of the dry box during the transfer process. This dust then went into the filters and solutions. To avoid this problem, solutions were made up in the dry box and filtration was done very quickly outside the dry box. Filtration of solvent and solution usually occurs in less than 15 seconds in the open air. To test that filtration outside the dry box did not change the light scattering signal, scattering at 90 degrees was measured on solvents on which filtering had been done in times as short as 5 seconds and as long as 15 seconds. The scattering signal from these experiments showed no dependence on time of filtration. Thus we are confident that rapid filtration outside the dry box did not change the solution or solvent properties enough to be measured and thus should not affect the molecular weight value determined.

\subsubsection{Determination of $\mathrm{dn} / \mathrm{dc}$}

The differential refractive index for SRM 1480 in DMAC at $30^{\circ} \mathrm{C}$ for light of wavelength $633 \mathrm{~nm}$ was determined using a LDC/Milton Roy Chromatix $\mathrm{KMX}-16$. The $\mathrm{KMX}-16$ has been calibrated against aqueous $\mathrm{NaCl}$ solutions following the data of Kruis [4]. Solutions of polyurethane prepared for the light scattering experiments were run within a day or so in the KMX-16 to obtain the $\Delta \mathrm{n}$. A linear least squares analysis of the $\Delta \mathrm{n}$ versus the concentration was carried out. The slope gave a $\mathrm{dn} / \mathrm{dc}$ of $0.0841 \mathrm{~mL} / \mathrm{g}$ with a standard deviation of $0.0051 \mathrm{~mL} / \mathrm{g}$. The data are shown in figure 5 .

\subsubsection{Light Scattering Methods}

Light scattering measurements on the polyurethane solutions in DMAC were made on a Brookhaven Instruments Model BI-200 light scattering apparatus. A 5 milliwatt $\mathrm{He}-\mathrm{Ne}$ laser was used as a light source. The laser beam is vertically polarized and a vertical polarizer was used in the detector optics so we have $V_{v}$ polarization for the scattered intensity. During any one day 3 or 4 solutions were made up, filtered into the light scattering cells which had teflon lined screw caps on them, and run. Often the solutions were kept in the dark overnight and run for a second time early the next day with little apparent change in the molecular weight.

\subsection{Analysis of Light Scattering Data}

Light scattering data at $V_{v}$ polarization from polymer solutions of concentration $c$ and scattering angle $\theta$ may be analyzed by fitting the scattering signal $\mathrm{I}(\theta, \mathrm{c})$ to

$$
I(\theta, c)=I(\theta, 0)+c I_{G} /\left((\sin \theta) \sum_{i j} C_{i j} c^{i} \sin ^{2 j}(\theta / 2)\right) \text {. }
$$

In eqn (1) $I_{G}$ is the scattering signal from the benzene working standard at $\theta=90^{\circ}$. 
In order to use eqn (1) for the estimation of molecular parameters, we must first decide how many terms on the right-hand side must be included to provide an adequate fit to the experimental data. The dependence of $c / I_{c}$, where $I_{c}=\sin \theta[I(\theta, c)-I(\theta, 0)] / I_{G}$, upon $c$ and upon $\sin ^{2}(\theta / 2)$ reflects solute-solvent interactions and solute size, respectively. Accordingly, preliminary scattering data for SRM 1480 were first analyzed as $c / I_{c}$ versus $\sin ^{2}(\theta / 2)$ at constant concentration and versus $c$ at constant scattering angle, to see whether a linear expansion (i.e., retaining only $\mathrm{C}_{00}, \mathrm{C}_{0_{1}}$, and $\mathrm{C}_{10}$ ) would provide an adequate fit. The analysis revealed that the linear approximation was adequate at concentrations below $0.014 \mathrm{~g} / \mathrm{mL}$. The next higher order terms, $\mathrm{C}_{20}$ and $\mathrm{C}_{0_{2}}$, were included in the final fit to show that the data were consistent with this hypothesis.

Thus we used for the final analysis

$$
\begin{aligned}
& I(\theta, c)=I(\theta, 0)+c I_{G} /\left\{\operatorname { s i n } \theta \left(C_{00}+C_{01} \sin ^{2}(\theta / 2)+\right.\right. \\
& \left.\left.C_{10} c+C_{11} c \sin ^{2}(\theta / 2)+C_{20} c^{2}+C_{02}\left(\sin ^{2}(\theta / 2)\right)^{2}\right)\right\}
\end{aligned}
$$

The coefficients in eqn (2) are related to the weight-average molecular weight $M_{w}$, molecular mean-square radius of gyration $R_{G}{ }^{2}$, and second and third virial coefficients, $A_{2}$ and $A_{3}$, by [5]:

$$
\begin{aligned}
\mathrm{M}_{w} & =\left(\mathrm{K}^{\prime} \mathrm{C}_{00}\right)^{-1} \\
\mathrm{R}_{\mathrm{G}}{ }^{2} & =3\left[\lambda_{0} /(4 \pi \mathrm{n}]^{2} \mathrm{C}_{01} / \mathrm{C}_{00}\right. \\
\mathrm{A}_{2} & =1 / 2 \mathrm{~K}^{\prime} \mathrm{C}_{10} \\
\mathrm{~A}_{3} & =1 / 3 \mathrm{~K}^{\prime} \mathrm{C}_{20} \\
\mathrm{~K}^{\prime} & =4 \pi^{2} \mathrm{n}_{\mathrm{B}}{ }^{2}(\mathrm{dn} / \mathrm{dc})^{2} /\left(\lambda_{0}{ }^{4} \mathrm{~N}_{\mathrm{A}} \mathrm{V}_{\mathrm{v}}{ }^{\mathrm{B}}\right)
\end{aligned}
$$

where:

$\lambda_{0}$ is the wavelength in vacuum of the scattered light, $632.8 \mathrm{~nm}$ in this work, $n$ and $n_{B}$ are the indices of refraction of the solvent and benzene taken as 1.435 [6] and 1.503 [5], respectively, dn/dc is the differential refractive index of the solution, measured as described in $6.2 .2, \mathrm{~N}_{\mathrm{A}}$ is Avogadro's number, taken as $6.022 \times 10^{23} \mathrm{~mol}^{-1}, \mathrm{~V}_{\mathrm{v}}{ }^{\mathrm{B}}$ is the Rayleigh ratio for the vertically polarized scattering of vertically polarized light from benzene, used for calibration and obtained as described in the following paragraph.

The "vertical-vertical" Rayleigh ratio $V_{v}$ is related to the Rayleigh ratio $R_{v}$ for the unpolarized scattering of vertically polarized He-Ne laser and the depolarization ratio $\mathrm{P}_{\mathrm{v}}$ for polarized light by:

$$
\mathrm{V}_{\mathrm{v}}{ }^{\mathrm{B}}=\mathrm{R}_{\mathrm{v}}{ }^{\mathrm{B}} /\left(1+\mathrm{p}_{\mathrm{v}}\right)
$$


Using the published [7] values for benzene

$$
R_{\mathrm{v}}^{B}=12.6 \times 10^{-6} \mathrm{~cm}^{-1}
$$

and $\mathrm{p}_{\mathrm{v}}=0.265$, we obtain

$$
V_{v}=9.96 \times 10^{-6} \mathrm{~cm}^{-1}
$$

\subsection{Results}

Eight independent sets of light scattering runs were made on SRM 1480 using DMAC as solvent. Each set consisted of four independently prepared solutions. The polymer for each solution was taken from a different sample vial. Two sets were discarded because the highest concentration in the run indicated a large contribution from $A_{3}$. One set at very low concentration was discarded due to the very small signal over solvent scattering at the lowest concentrations.

Each of the five remaining sets consisted of scattering measurements on solvent and four solutions for at least seven scattering angles between 30 and 150 degrees. The scattered intensities in each set were fitted by least squares to eqn (2), and the results were used to calculate $M_{w}, A_{2}$ and $A_{3}$ using eqns (3)-(7). No estimate was made of $R_{G}{ }^{2}$ at these low molecular weights. The values of $\mathrm{M}_{w}, A_{2}$, and $A_{3}$ obtained from the five sets were then averaged. The resulting mean values and sample standard deviations are given in table 2. Light scattering gave a weight average molecular weight of about $4.73 \times 10^{4} \mathrm{~g} \mathrm{~mole}^{-1}$ with a standard deviation of $0.33 \times 10^{4} \mathrm{~g} \mathrm{~mole} \mathrm{e}^{-1}$ and a value of $\mathrm{A}_{2}$ of $0.00130 \mathrm{~mol} \mathrm{~cm} / \mathrm{g}^{2}$.

From the data in table 2 the average value of $A_{3}$ is much smaller than its standard deviation. This suggests that the contribution from the term in $A_{3}$ is not significant in this measurement. Furthermore, if $A_{3}$ were to contribute significantly to the extrapolation to zero concentration scattering to obtain the molecular weight, then $1.5 \mathrm{~A}_{3} \mathrm{c}_{\mathrm{m}}$, where $c_{m}$ is the maximum concentration used in the fitting scheme, would have a value on the order of $A_{2}$. If we use the average value of $A_{3}$ from table 2, this product is two orders below $A_{2}$. If we use the maximum value of $A_{3}$ found in table 2 this product is less than the standard deviation in $A_{2}$. Finally, the Zimm plot of one set of data, Figure 6, shows no curvature in the concentration at fixed angle plots. This too indicates there is negligible contribution from $A_{3}$. Thus we are confident that $A_{3}$ makes no significant contribution in this concentration range to the extrapolation of the light scattering results to zero concentration. 


\subsection{Estimation of systematic errors}

We now list the likeliest sources of systematic error in the determination of weight-average molecular weight by light scattering described in the preceding sections, and attempt to estimate upper limits for their magnitudes. For this purpose, we employ a scheme similar to that used in Ref. [5] for the estimation of systematic errors in SRM's 1482,1483 and 1484 .

We shall use the following convention regarding the signs to be assigned to error terms: An error which, if present, would cause the certificate value of $M_{w}$ to be greater than the true value will be given a plus sign; an error which would cause the certificate value to be less than the true value will be given a minus sign. For sources for which the error could be of either sign, no sign will be given.

\subsubsection{Indices of Refraction}

As in Ref. [5], we believe that 0.18 is a safe upper limit for systematic errors in $\mathrm{M}_{w}$ arising from errors in the literature values of solvent index of refraction.

5.5.2. Literature Value of $\mathrm{dn} / \mathrm{dc}$ for Aqueous $\mathrm{NaCl}$ and Calibration of the Differential Refractometer

Calibration of the differential refractometer required interpolation of the data of Ref. [4] to the $633 \mathrm{~nm}$ wavelength used for the lightscattering measurements. We estimate the possible error in the interpolated values of $\Delta n$ as $0.6 \%$, due primarily to possible errors in the interpolation process. The calibration factor measured for our differential refractometer had a relative standard deviation ( $r s d$ ) of $0.038 \%$, with 11 degrees of freedom. The critical t-value at $1 \%$ confidence limits is 3.1 , leading to an estimated error in $\mathrm{dn} / \mathrm{dc}$ of $0.038 \times 3.18$, or 0.128 . Putting these two estimates together with an allowance for possible linearity errors in the refractometer, we believe that a safe upper limit for errors in $\mathrm{dn} / \mathrm{dc}$ is 18 , which would give rise to an error in $\mathrm{M}_{\mathrm{w}}$ of $2 \%$.

\subsubsection{Measured Value of $\mathrm{dn} / \mathrm{dc}$ of SRM 1480}

The differential refractive index $\mathrm{dn} / \mathrm{dc}$ of SRM 1480 in dimethyl acetamide (DMAC) at a temperature of $30^{\circ} \mathrm{C}$. was determined using a LDC/Milton Roy Chromatix Model KMX-16 differential refractometer. The mean value obtained for $\mathrm{dn} / \mathrm{dc}$ was $0.0841 \mathrm{~mL} / \mathrm{g}$, with a standard deviation of the mean of $0.00064 \mathrm{~mL} / \mathrm{g}$ and 10 degrees of freedom. The relative standard deviation is then $0.00064 / 0.0841$, or $0.76 \%$. Critical $t$-value at $1 \%$ confidence limits is 3.2 , giving an estimated error of $0.76 \% \times 3.2$, or 2.48 , and the resulting error in $\mathrm{M}_{w}$ is twice this or 4.88 . 
For the He-Ne laser employed in this work, uncertainties in the wavelength of the radiation are completely negligible compared with errors from other sources.

\subsubsection{Rayleigh Ratio of Benzene.}

For benzene at $632.9 \mathrm{~nm}$, Ref. [7] gives: $R_{V}, \mathrm{v}+\mathrm{H}=12.6 \times 10^{-6} \mathrm{~cm}^{-1}$ and $\rho_{\mathrm{v}}=0.265$, giving $\mathrm{R}_{\mathrm{VV}}=\mathrm{R}_{\mathrm{V}, \mathrm{V}+\mathrm{H}} /\left(1+\rho_{\mathrm{v}}\right)=9.96 \times 10^{-6} \mathrm{~cm}^{-1}$. Abbreviate $\mathrm{R}_{\mathrm{V}, \mathrm{V}+\mathrm{H}}$ and $\rho_{\mathrm{v}}$ by $\mathrm{R}$ and $\rho$, respectively. The authors of Ref. [7] apparently believe that their R-values are accurate to 28 (systematic). They quote a relative standard deviation for their R-value for benzene of $0.21 / 12.63$, or $1.7 \%$. They do not give estimates of either accuracy or precision for their values of $\rho$. However, $\rho$ is obtained as the ratio of two intensities, the larger of which is, or is close to, the intensity measured for the determination of $\mathrm{R}$. The photomultiplier detectors were apparently operated in the current mode, and it seems reasonable to suppose that the absolute error in the smaller intensity is the same as that of the larger, and that the relative error in the larger is the same as that in $R$. Then if $r$ is the rsd of $R$, we have for the standard deviation in $\rho: \operatorname{sd}(\rho)=r \sqrt{ }\left(1+\rho^{2}\right)$ and $\operatorname{rsd}(1+\rho)=[r /(1+\rho)] \sqrt{ }\left(1+\rho^{2}\right)$, and combining this with the rsd in $R$, we have $\operatorname{rsd}\left(\mathrm{R}_{\mathrm{VV}}\right)=[\mathrm{r} /(1+\rho)] \sqrt{2}\left(1+\rho+\rho^{2}\right)$, which is about $1.3 \mathrm{r}$ for $\rho=0.265$. Assuming a $t$-factor of 3 (the number of degrees of freedom is not given) and $r=1.78$, we obtain an uncertainty of $3 \times 1.3 \times 1.78=6.68$, which we combine (by root-sum-squares) with the stated inaccuracy of $2 \%$ to obtain $6.9 \%$, which we round to $7.0 \%$.

\subsubsection{Polarizer errors.}

There are four of these: First, the "vertically polarized" laser beam actually contains "horizontally polarized" components for two reasons: First, the polarizer inside the laser head lets through a small fraction $\epsilon$ of the "wrong" polarization; Second, the principal axis of polarization of the light from the laser may not be exactly perpendicular to the plane of the incident and scattered beams. Both will cause light assumed to be vertically polarized to contain a small admixture of horizontally polarized light. The effect upon scattering signals from SRM 1480 will be slight, but the effect upon the benzene calibration signals is to change the effective Rayleigh ratio that should have been used from the $R_{\mathrm{Vv}}$ value toward the $R_{\mathrm{V}, \mathrm{V}+\mathrm{H}}$ value. The resulting error in $\mathrm{M}_{\mathrm{w}}$ is $\rho \epsilon /(1-\epsilon)$ for the first effect and $\rho \tan ^{2} \alpha$, where $\alpha$ is the angular mis setting, for the second. The error from both effects together is $\rho[\epsilon /(1-$ $\left.\epsilon)+\tan ^{2} \alpha\right]$.

Second, in an exactly analogous way, the analyzing polarizer in front of the detector may be non-ideal and/or mispositioned. In this case, let $\delta$ be the contribution from the nonideality of the polarizer, and let $\beta$ be the angle of mis-setting. The resulting expression for the error is then: $\rho\left[\delta /(1-\delta)+\tan ^{2} \beta\right]$. 
Finally, since all these errors are of the same sign, we add them to get: $\rho\left[\epsilon /(1-\epsilon)+\tan ^{2} \alpha+\delta /(1-\delta)+\tan ^{2} \beta\right]$. Take $\epsilon=\delta=1 / 500, \alpha=5^{\circ}$, and $\beta=3^{\circ}$, and $\rho=0.265$. Then the possible error is $0.265[.0020+.0077$ $+.0020+.0027]=0.0038=0.48$. This error will cause the apparent Rayleigh ratio from solute, and hence the apparent $M_{w}$, to be less than the true value, hence the error is given as -0.48 .

\subsubsection{Ratio of Working Standard Scattering to Sample Scattering}

Since photon counting techniques were employed, there should be no systematic errors from this source.

\subsubsection{Solvent Density}

For the density of DMAC at $30{ }^{\circ} \mathrm{C}$, we used the value $0.9323 \mathrm{~g} / \mathrm{mL}$ [6]. It is difficult to doubt that this value is accurate to 0.18 or better. The resulting error on $\mathrm{M}_{\mathrm{w}}$ is [5] just $0.1 \%$.

\subsubsection{Solute Weights}

For the runs actually used in the final determination of $M_{w}$ for $S R M$ 1480 , the concentrations employed were nominal $0.1,0.15,0.2$, and 0.4 $\mathrm{g} / \mathrm{L}$, and the solvent weights were chosen so that the solute weights were always about $0.1 \mathrm{~g}$. Then using the error limit of $0.1 \mathrm{mg}$ we usually assign to the Mettler balances used in this work, we have errors in the solute weights of 0.18 (and utterly negligible errors in solvent weights). The error in $M_{w}$ is then the error in solute weights, or about 0.18 .

\subsubsection{Reflection Correction}

The index of refraction of DMAC at $20^{\circ} \mathrm{C}$ and sodium $\mathrm{D}$ line wavelength is given [8] as 1.4384. Neither the wavelength nor the temperature is correct for our experiments, but this ought to be adequate for estimating what will turn out to be an extremely small error. The index of refraction of the sample cell is given by the vendor as 1.514 . This gives a reflection factor $f$ of 0.0007 . Comparison calculations of $M_{w}$ show the resulting error to be 0.0048 , or for our purpose 0.08 .

\subsubsection{Instrumental Misalignment}

Alignment was carried out to give values of scattering intensity times the sine of the scattering angle constant to $1 \%$, and the resulting error in $\mathrm{M}_{\mathrm{w}}$ should be not greater than this amount. We believe the scattering angle offset error is no more than 0.28 . Comparison calculations of $\mathrm{M}_{\mathrm{w}}$ show the resulting error to be 0.768 . We then estimate the error from both components to be the sum: $1.8 \%$.

\subsubsection{Refraction Correction}

A detailed analysis of the optical geometry of the light scattering instrument employed in this work can not be carried out, since the main detector optics unit was inaccessible. However, rough analyses based on 
guesses about the internal geometry of the detector unit lead to a likely error of about $-0.3 \%$. A reasonable error limit might then be about twice this, or $-0.6 \%$.

\subsubsection{Anisotropy of Solute}

We have no data on the optical anisotropy of materials like SRM 1480 . We have therefore estimated $H_{\mathrm{v}} / \mathrm{V}_{\mathrm{V}} \equiv \rho_{\mathrm{v}}$ experimentally for a relatively concentrated solution ( 0.48$)$ of SRM 1480; then

$\mathrm{M}_{w}$ (corrected) $=\mathrm{M}_{w}$ (apparent) $\times\left[1-(4 / 3) \rho_{\mathrm{v}}\right]$. In the following, let $I$ be counts per second over a 2 second interval. First, with the detector-side analyzer set to "vertical", we measured differences

I(solution) - I (solvent) of about 5807. Then, with the detector-side analyzer set to "horizontal", we obtained ten differences

$\Delta=I$ (solution) - I (solvent). The ten values of $\Delta$ obtained have a mean of 6.9 , a standard deviation of 11.9, and a standard deviation of the mean of 3.8. Then the correction factor to be applied to $M_{w}$ is

$(1-(4 / 3) \times 6.9 / 5807)=0.9984$. The Student $t$-factor for 9 degrees of freedom and $1 \%$ confidence limits is 3.250 . Then we estimate the relative uncertainty in $\mathrm{M}_{w}$ due to the uncertainty in $\triangle$ as:

$3.8 \times 3.250 \times(4 / 3) / 5807=0.0028$, or 0.38 .

\subsubsection{Cutoff of Virial Expansion}

As described in 5.3., the solution concentrations used for the final analyses were limited to a region where linear terms in $c$ and $\mathrm{X} \equiv \sin ^{2}(\theta / 2)$ appeared to suffice. Comparison calculations of $\mathrm{M}_{w}$ show that allowing terms in $c^{2}, c X$, and $X^{2}$ in the analyses changes the calculated values of $\mathrm{M}_{w}$ by $6.318,-0.368$, and 1.28 , respectively. However, the first of these results in a negative third virial coefficient, which we reject as unphysical. We therefore take the larger in magnitude of the remaining two: the term in $X^{2}$. Since allowing a term in $\mathrm{X}^{2}$ increases the calculated value of $\mathrm{M}_{w}$, the implied error due to forcing the term in $X^{2}$ to be zero is negative: -1.28 .

\subsubsection{Solute Degradation}

Time-dependence studies of apparent molecular weight, described in 5.1., showed decreases in apparent molecular weight with time, which we tentatively ascribe to sample degradation. From the fact that the changes in apparent $M_{w}$ were less than 58 in 12 hours and the structure of the experiments, we conclude that a safe limit for error due to sample degradation is $-5.0 \%$.

\subsubsection{Summary}

The sum of the absolute values of the individual error estimates in 5.5.1. through 5.5.15. is 23.48. We reject this as an overly pessimistic estimate for the combined systematic error from all sources, since it would only be obtained if the individual errors were all at their maximum magnitudes and of the same sign. We believe that a more realistic estimate of systematic error limit may be obtained by first adding all the 
signed (negative) errors, i.e., those in 5.5.6., 5.5.12., 5.5.14., and 5.5.15., to obtain a total signed error contribution of -7.28 . We then combine this figure by root-sum-squares with the remaining (unsigned) individual estimates to obtain $11.5 \%$. This estimate in turn seems too low, since the individual contributions to it are not numerous and of roughly equal magnitude, but are dominated by three roughly equal contributions (5.5.3., 5.5.5., and 5.5.15.) which together would add up to about $17 \%$. Putting all this together, our best guess for a likely limit of systematic errors from all sources is $15 \%$, as shown on the certificate for SRM 1480.

\subsection{Conclusions}

The weight average molecular weight of SRM 1480 , a model polyurethane, was determined to be $4.73 \times 10^{4} \mathrm{~g} \cdot \mathrm{mole}^{-1}$. The intrinsic viscosity of SRM 1480 in THF was found to be $43.8 \mathrm{~mL} / \mathrm{g}$.

The SEC of SRM 1480 in THF as received in the bottle exhibited concentration dependent peak positions even for low concentrations. The addition of 0.01 moles per liter $\mathrm{LiBr}$ to the THF was found to alleviate this problem. This low concentration of LiBr did not however change the PS calibration of the SEC columns. 
Table 1 Viscosity Number as a Function of Concentration of SRM 1480

( THF at $30^{\circ} \mathrm{C}$ )

Concentration

$\mathrm{g} / \mathrm{mL}$

0.005004

0.007504

0.007505

0.002502

0.005003

0.002501

Results of fit

Limiting Viscosity number

Standard Deviation
Viscosity No.

$\mathrm{mL} / \mathrm{g}$

48.10

50.01

49.96

45.54

48.04

45.69

43.80

0.17 
TABLE 2

Molecular Weight, $A_{2}$ and $A_{3}$ for SRM 1480

$\begin{array}{lccc}\begin{array}{l}\text { Run } \\ \text { Label }\end{array} & \begin{array}{c}\mathrm{M}_{\mathrm{W}} \times 10^{-3} \\ \mathrm{~g} / \mathrm{mol}\end{array} & \begin{array}{c}\mathrm{A}_{2} \\ \mathrm{~cm}^{3} / \mathrm{g}^{2}\end{array} & \begin{array}{c}\mathrm{A}_{3} \\ \mathrm{~cm}^{6} / \mathrm{g}^{3}\end{array} \\ \text { LS1129 } & 46.8 & 0.00128 & 0.0057 \\ \text { LS1128 } & 48.7 & 0.00138 & -0.003 \\ \text { LT12456 } & 52.0 & 0.00197 & -0.069 \\ \text { LT125D6 } & 44.0 & 0.00098 & 0.045 \\ \text { LU1121A } & 44.7 & 0.00087 & 0.047 \\ \text { Average } & 47.3 & 0.00130 & 0.0051 \\ \text { Standard } & & & \\ \text { Deviation } & 3.3 & 0.00043 & 0.047\end{array}$


[1] C. Guttman, J. Maurey, P. Verdier, C. Han and F. Wang, NISTIR 4788, 1992

[2] N.D. Hann, J Polymer Sci A-1, Polymer Chem. 6, 1331-1339

[3] G. Glocker, "Polymer Characterization by Liquid Chromatography," Journal of Chromatography Library - Vol. 34, Elsevier, Amsterdam, 1987, $\mathrm{Pg} 390$ and following.

[4] A. Kruis, Z. Physik. Chec. B 34, 13 (1936).

[5] C. C. Han, P. Verdier and H. Wagner, J. Res. NBS 83, 185-193 (1978).

[6] J. A. Riddick and W. B. Bunger, "Organic Solvents," Wiley Interscience, pg 450, New York, 1970.

[7] W. Kaye and J. B. McDaniel, Applied Optics, 13, 1934 (1974).

[8] "High Purity Solvent Guide", Burdick \& Jackson Laboratories, Inc. Second Edition. 


\section{Captions}

Figure 1. Homogeneity testing using SEC after bottling of SRM 1480. SEC of samples from four different bottles shows neither bottle to bottle variation nor within bottle variation.

Figure 2. Plot of viscosity number versus concentration for SRM 1480 in THF.

Figure 3. Effect of concentration variation of SRM 1480 in "as received " $\mathrm{THF}$ for concentrations from $0.001 \mathrm{~g} / \mathrm{mL}$ to $0.0001 \mathrm{~g} / \mathrm{mL}$. The left most peak is $0.001 \mathrm{~g} / \mathrm{mL}$ of SRM 1480 in $\mathrm{THF}$ and the right most peak is the signal for $0.0001 \mathrm{~g} / \mathrm{mL}$. RI signals on all SEC are normalized so that maximum of peak at each concentration is 1.0 for ease of seeing distribution and peak movement. (SEC columns are different from those used in figure 1.)

Figure 4. Little or no concentration variation of the peak position is seen with the addition of $0.01 \mathrm{~mol} / \mathrm{L} \mathrm{LiBr}$ to the THF. This is to be compared to figure 3 above. Concentration range is from $0.001 \mathrm{~g} / \mathrm{mL}$ to $0.000125 \mathrm{~g} / \mathrm{mL}$ of SRM 1480 .

Figure 5. Change in refractive index from solution to solvent as a function of concentration for SRM 1480 in DMAC. The slope of this line is $(\mathrm{dn} / \mathrm{dc})$.

Figure 6. Example of Zimm plot for one of the runs of SRM 1480. Lines are calculated values and points are experimental data. 


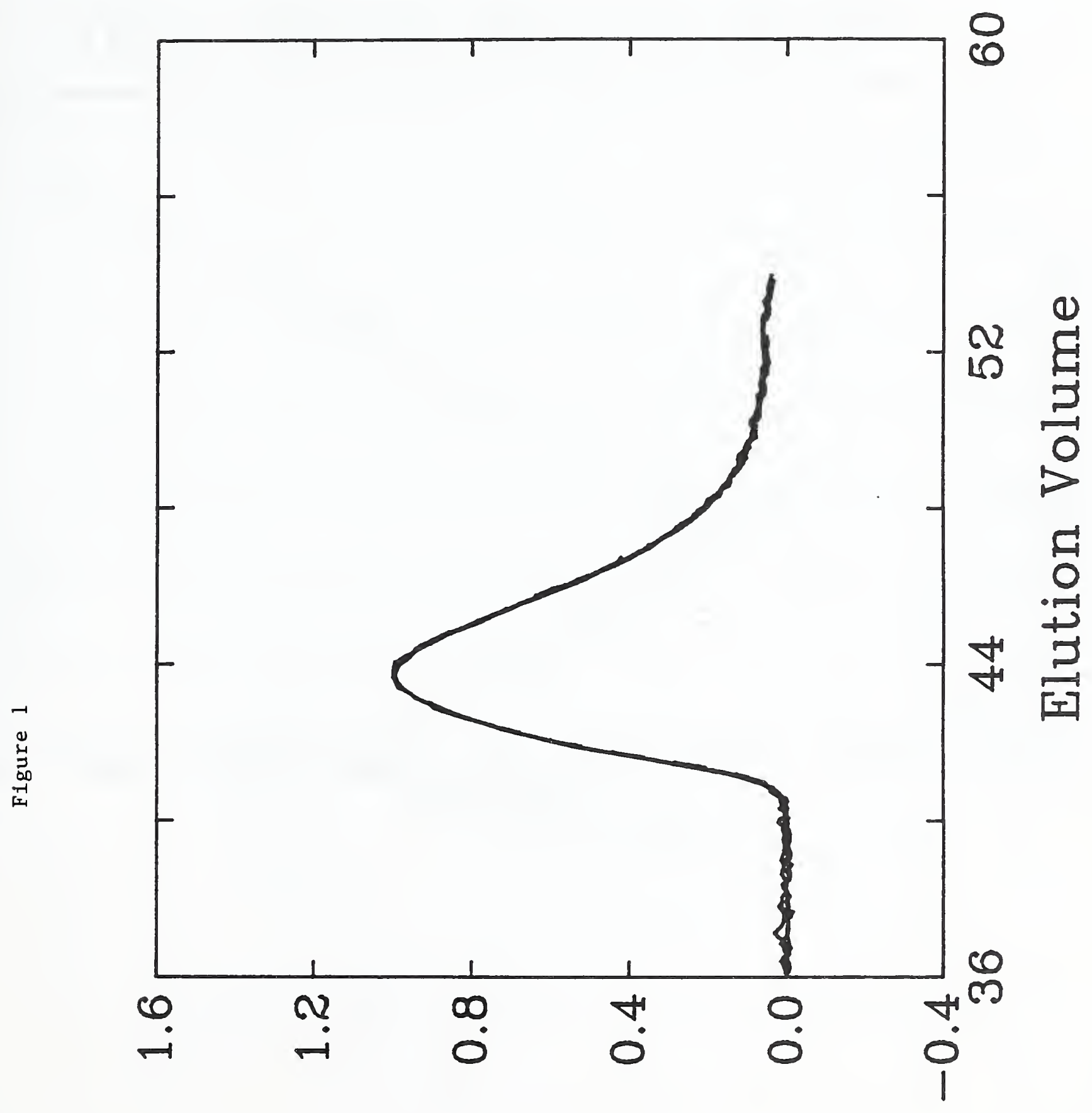

[อนจิ!S Iม 
Figure 2

\section{Intrinsic Viscosity of SRM 1480}

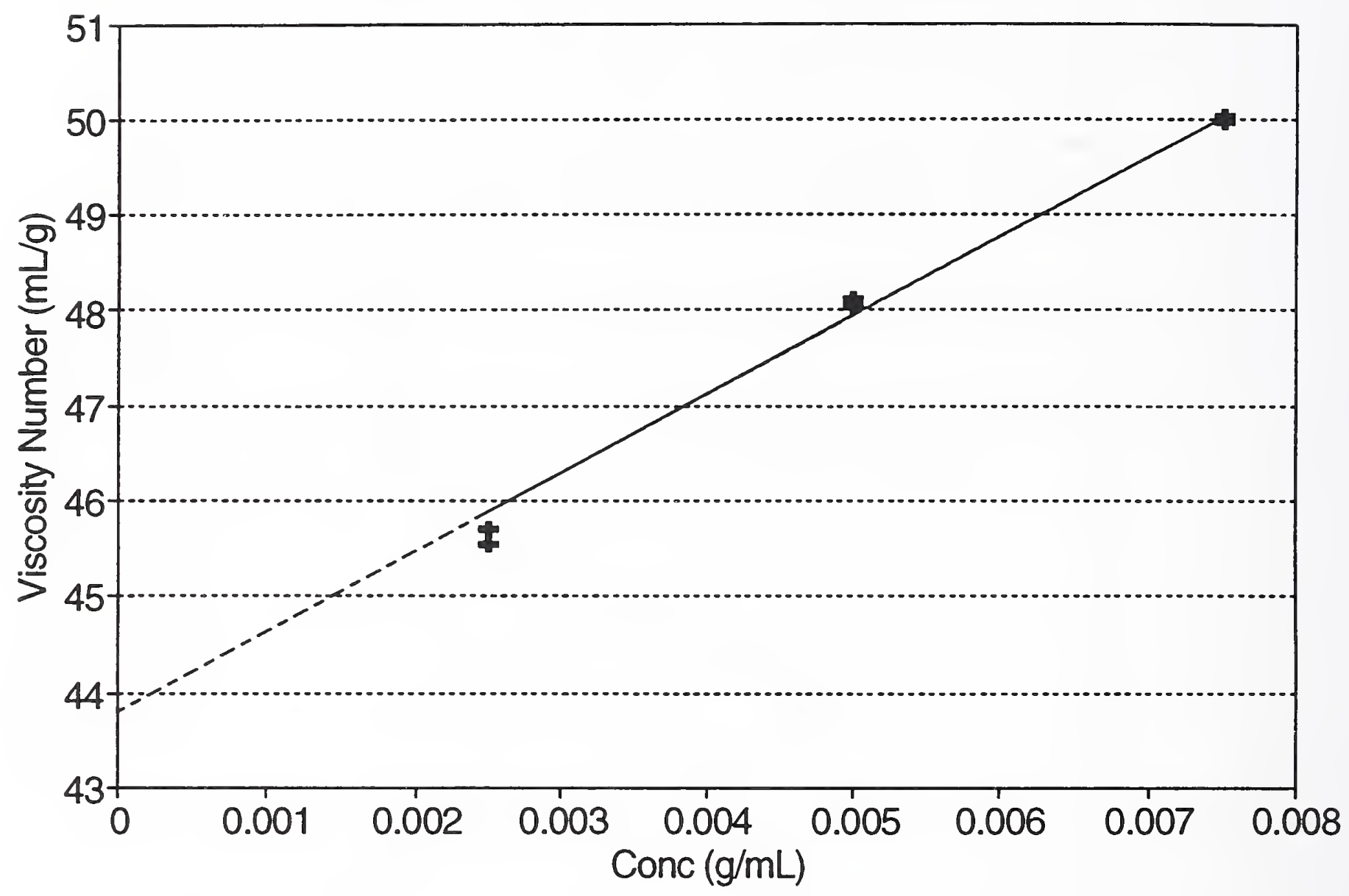




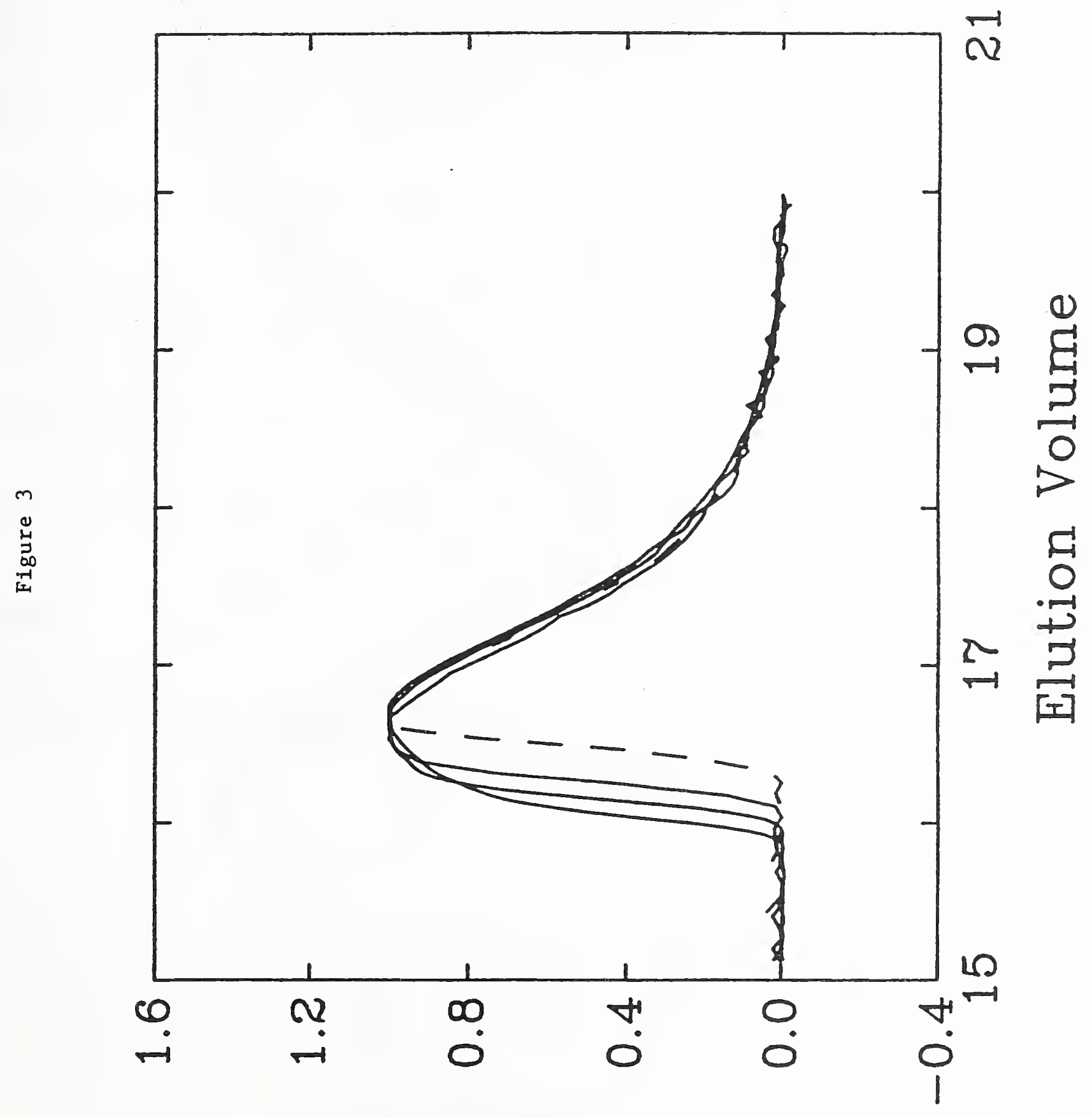

[อนภำ IY 


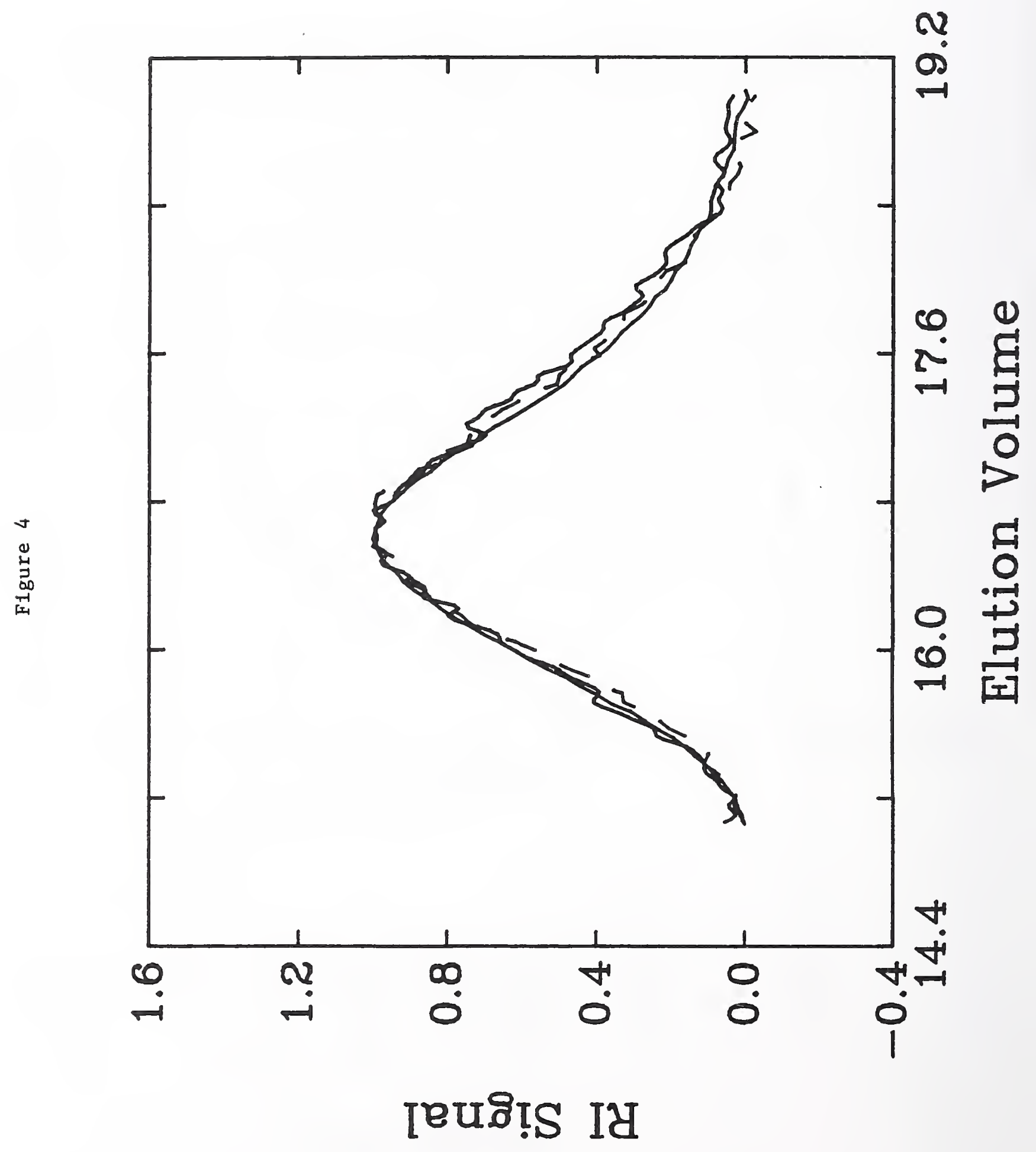


Figure 5

\section{Determination of $\mathrm{dn} / \mathrm{dc}$ for SRM 1480 in DMAC}

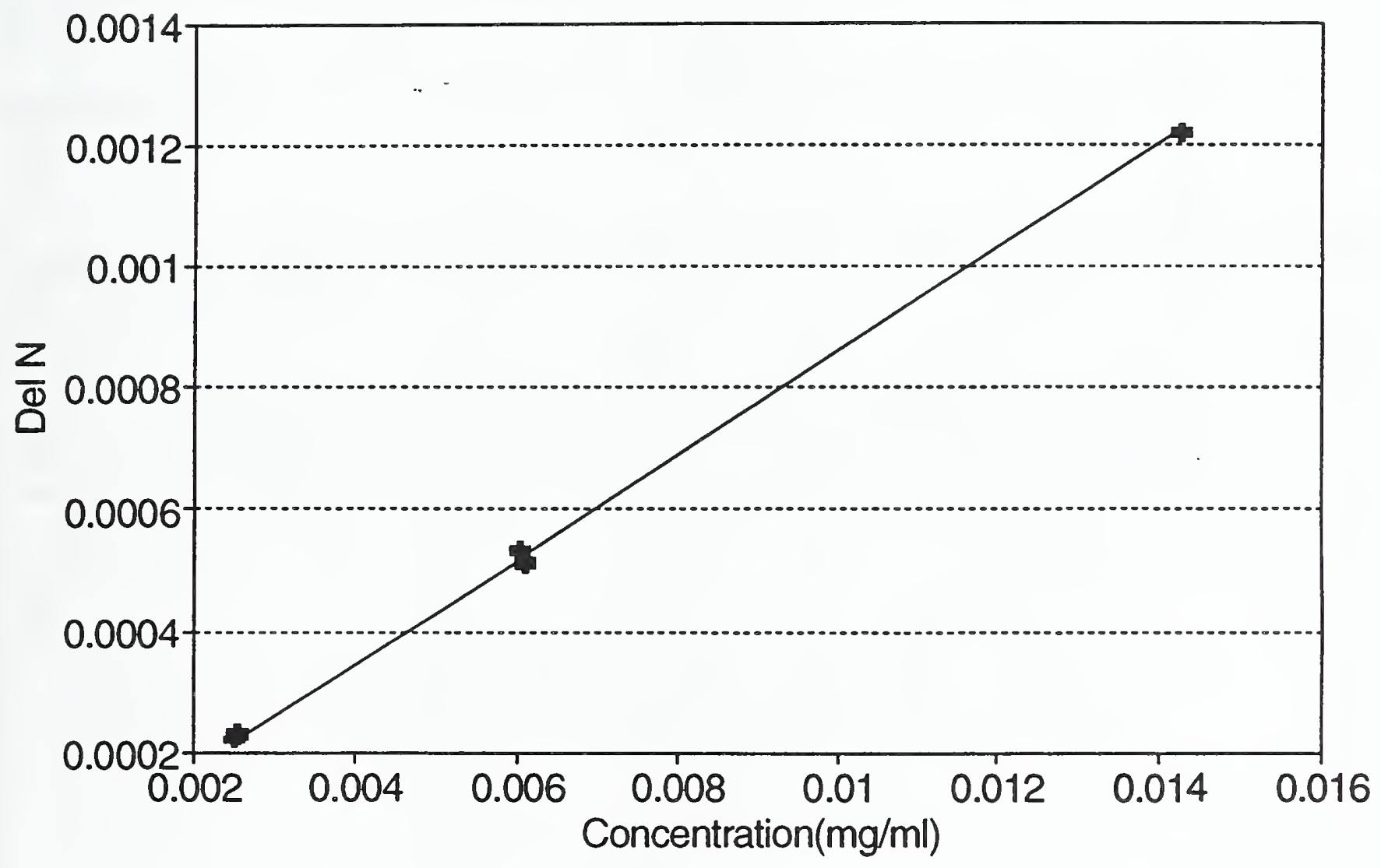




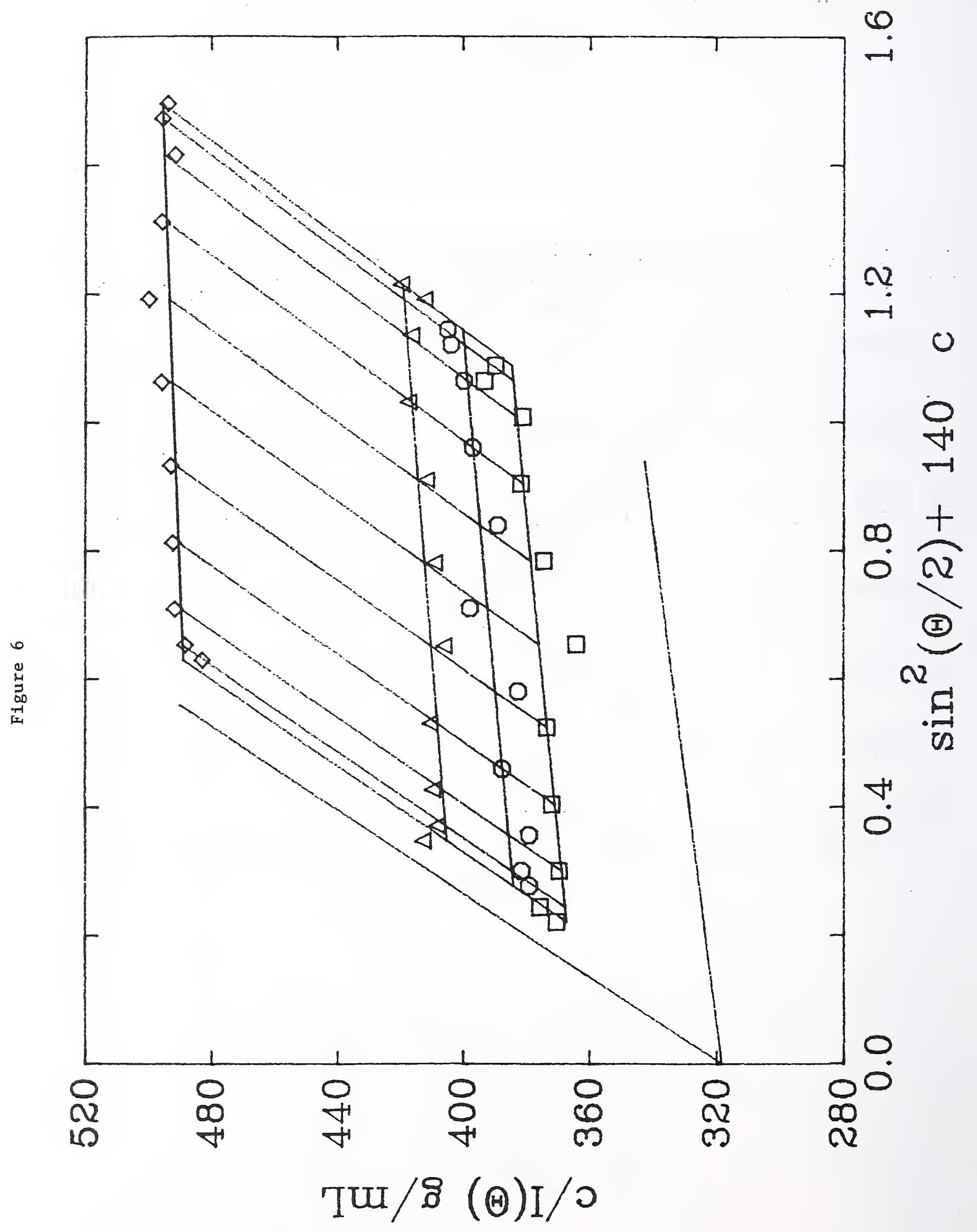


NIST-114A

(REV. 3-80)
U.S. DEPARTMENT OF COMMERCE

NATIONAL INSTITUTE OF STANDARDS AND TECHNOLOGY

BIBLIOGRAPHIC DATA SHEET
1. PUBLCATION OR REPORT NUMBER

- NISTIR 4837 ...

2. PERFORMINO ORCANIZATION AEPORT NUMBER

3. PUBUCATION DATE

July 1992

4. TITLE AND SUBTITE

Determination of the Welght Average Molecular Weight of SRM 1480

5. AUTHOR(S)

C. M. Guttman, J.R. Maurey, P.H. Verdier

6. PERFORLINO ORQANIZATION (IF JOINT OR OTHEA THAN MIST, SEE INSTAUCTIONS)

U.S. DEPARTMENT OF COMMEACE

MATIONAL INSTITUTE OF STANDARDS AND TECHNOLOBY

CATHERSBUAQ, MD 2089

7. CONTRACT/GRANT NUMBER

8. TYPE OF REPORT AND PERIOD COVERED

9. SPONSORING ORGARIZATION RAME AND COMPLETE ADDRESS (STREET, CITY, STATE, ZIP)

10. SUPPLEMENTARY NOTES

11. ABSTRACT (A 200-WORD OR LESS FACTUAL SUMMARY OF MOST SIOMIFICANT IMFORMATIOH. IF DOCUMEMT IMCLUDES A SIOMIFICAMT BIBLOQRAPHY OA UTERATURE SURVEY, MENTION IT HERE)

The characterization of a polyurethane standard reference material, SRM 1480, is described. The weight-average molecular weight of SRM 1480 by light scattering was determined to be $4.73 \times 10^{4} \mathrm{~g}$ mole-1 with a sample standard deviation of the mean of $0.33 \times 10^{4} \mathrm{~g} \cdot \operatorname{mole} \mathrm{e}^{-1}$, based on 4 degrees of freedom. A systematic error limit of 158 is estimated for this determination. The intrinsic viscosity of SRM 1480 in THF was also measured.

The Size Exclusion Chromatography (SEC) of SRM 1480 in THF as received in the bottle was found to exhibit concentration dependent peak positions even for low concentrations. The addition of 0.05 moles per liter LiBr to the THF was found to alleviate this problem. This low concentration of LiBr did not change the Polystyrene calibration of the SEC columns.

12. KEY WORDS (6 TO 12 ENTAIES; ALPHABETICAL ORDER; CAPITALIZE OHLY PROPER MAMES; AND SEPARATE KEY WOADS QY SEMICOLONS) Standard Reference Material, SRM, Polyurethane, Size Exclusion, Chromatography, Calibration Standard, Urethane, Light Scattering

FOR OFFICIAL DISTAIBUTION. DO NOT RELEASE TO MATIONAL TECHMICAL IMFORMATION SERVICE (NTIS).

ORDER FROM SUPERINTENDENT OF DOCUMENTS, U.S. OOVERHMENT PAINTINO OFFICE, WASHINOTON, DC 20402.

ORDER FROM MATIONAL TECHMICAL INFORMATION SERVCE (NTIS), SPRIMOFIELD, VA 22161.

14. HUMBER OF PAINTED PAGES

26

15. PRICE

$\mathrm{A03}$ 

